\title{
A nomenclatura das escolas públicas estaduais de Curitiba-PR: um estudo sobre genealogia e dominação simbólica
}

\author{
Luciana Podlasek ${ }^{1}$
}

\begin{abstract}
Resumo: Em Curitiba-PR existem atualmente 161 escolas públicas estaduais regulares de ensino básico, que atendem estudantes de variadas origens sociais. A formação dessa rede de ensino faz parte do processo histórico brasileiro, em que as demandas pela escolarização pública passaram a ser uma das grandes pautas das conquistas sociais, principalmente para as classes populares. A escola, a começar pela definição de seu nome, seria o espaço de reafirmação simbólica da superioridade intelectual e moral dos tradicionais grupos que dominam a política paranaense. Para o jovem periférico que adentra esse espaço, seria uma advertência sobre o papel subalterno que é imposto, para ele e para sua classe, no meio social. Nesse raciocínio, a partir de referenciais classistas, interesses políticos e princípios de dominação simbólica, torna-se viável a realização de estudos genealógicos e prosopográficos da nomenclatura das escolas públicas estaduais da capital paranaense.
\end{abstract}

Palavras-chave: Escolas públicas de Curitiba - PR. Dominação simbólica. Nomenclatura. Genealogia. Prosopografia.

\section{The nomenclature of state public schools in Curitiba-PR: a study on genealogy and symbolic domination}

\begin{abstract}
In Curitiba-PR there are currently 161 regular state public schools of basic education, which serve students of various social origins. The formation of this educational network is part of the Brazilian historical process, in which the demands for public schooling have become one of the great guidelines of the social achievements, especially for the popular classes. The school, starting with the definition of its name, would be the space of symbolic reaffirmation of the intellectual and moral superiority of the traditional groups that dominate the paranaense politics. For the young peripheral who enters this space, it would be a warning about the subordinate role that is imposed, for him and for his class, in the social environment. In this reasoning, based on class references, political interests and principles of symbolic domination, it becomes feasible to carry out genealogical and prosopographic studies of the nomenclature of state public schools in the state capital.
\end{abstract}

Keywords: Public schools of Curitiba - PR; Symbolic domination; Nomenclature; Genealogy; Prosopography.

*Recebido em 30/05/2018.

*Aceito em 15/06/2018.

\footnotetext{
${ }^{1}$ Licenciada e bacharel em História e mestranda em Sociologia pela Universidade Federal do Paraná (UFPR). Email: lucianabenario@gmail.com
} 
O direito à educação pública e universal é uma conquista das mais importantes no Brasil. Porém o acesso ao ensino público para todos os cidadãos é um direito que foi alcançado num processo lento, falho e marcado pela constante exclusão das classes menos abastadas, ao menos até meados do século XX. A presença na escola e o acesso à formação educacional nem sempre foram considerados um direito do todo cidadão, e um dever do Estado. Durante muito tempo, a educação era um privilégio para aqueles que podiam pagar por ela, seja na forma de professores preceptores, ou escolas particulares, muitas delas com caráter confessional. (BOMENY, 2017).

Nos longos períodos da colonização e do Império, o modelo de educação no Brasil pouco mudou, sendo orientado por interesses elitistas e conservadores, o que de fato excluía grande parte das classes populares do acesso a uma verdadeira formação escolar. A classe dominante tradicional brasileira (OLIVEIRA, 2001) e sua secular dominação econômica, política e ideológica, manteve a escola como um espaço de privilégio, destinado àqueles que deveriam se perpetuar nos postos de comando e de destaque na Nação. (SOUZA, 2015).

Mesmo que já em 1827, durante o governo do Imperador D. Pedro I, tenha sido publicada a lei das "Escolas de Primeiras Letras" (BRASIL, 1827), que obrigava a instalação nas cidades e vilas de instituições públicas para a alfabetização das crianças, na prática essa medida não funcionou. Isso ocorreu porque a publicação da referida Lei não foi acompanhada da devida estruturação física e funcional para a empreitada. Nas cidades maiores, algumas escolas chegaram a funcionar, mas nas vilas e interiores do Brasil, a carência de espaços físicos, de profissionais do magistério devidamente capacitados e a baixa remuneração para os docentes tornaram o projeto ineficiente. (NASCIMENTO [s/d]).

Com a proclamação da República em 1889, e consequente separação entre Estado e Igreja, abre-se caminho para a implantação de um sistema de educação laica no país. Contudo, mesmo com essa transformação importante, ainda não existia uma verdadeira política educacional inclusiva. Algumas mudanças de caráter legal, como a descentralização da organização escolar (MAGALHÃES [s/d]), ou novas influências ideológicas, como a forte concepção positivista que marcou parte do governo da Primeira República (SILVA [s/d]), não foram suficientes para a garantia da inclusão das classes populares num sistema educacional que se equiparasse ao que era destinado para os membros das classes dominantes tradicionais.

Percebe-se claramente que a adoção do sistema republicano não carreou mudanças na mentalidade das elites brasileiras no que concerne à educação, que permaneceu com as mesmas características aristocráticas do período colonial/escravocrata. A educação das crianças de classes populares continuou a limitar-se a uma preparação para o 
trabalho e ao adestramento em ofícios manuais, em substituição à educação formal. $\mathrm{O}$ fato de existir um sistema alternativo de educação para essas crianças denota, antes de mais nada, o elitismo do sistema de ensino brasileiro e sua incapacidade em absorver alunos provenientes de camadas mais pobres da população. (RAMOS, 2001, p.05).

Na década de 1930, as políticas do Estado Novo de Getúlio Vargas definiram qual seria o novo caminho da formação educacional dos estudantes brasileiros pertencentes aos meios populares: a formação para o trabalho (RIBEIRO, 1993). Mesmo assim, a inclusão no sistema de ensino e a formação dos estudantes não apresentaram significativas melhora. Após o período do Estado Novo, durante o segundo governo de Getúlio Vargas (1950-1954), os índices de desenvolvimento da educação no país permaneciam preocupantes.

\footnotetext{
Pelos dados do Censo Demográfico de março de 1951, a população brasileira era então de 51.944.397 habitantes. A população em idade escolar, de 5 a 9 anos, era de 7.015.527. O número de matrículas no ensino primário totalizava 5.175.887. Mas o Censo mostra mais. O número total de matrículas em todos os graus de ensino somava 6.118.842. Este número considera todos os níveis, do primário ao superior, para uma população em idade escolar (de 5 a 19 anos) de 18.826.409. A taxa de analfabetismo era da ordem de 52\%. (BOMENY, 2017).
}

A implantação do regime militar em 1964 reforçou o caráter tecnicista da educação pública, que deveria formar bons agentes para o mercado de trabalho. Mesmo com a redemocratização do país, e com as novas diretrizes educacionais estabelecidas pela Constituição de 1988, a educação brasileira, e em especial a escola pública, seguem enfrentando enormes dificuldades e desafios. A inclusão das classes populares, e a garantia de um ensino democrático, e qualidade e universal permanecem como grande impasse, que está por ser superado desde o período colonial. (RIBEIRO, 1993).

Diante desse histórico marcado pela exclusão da maioria da população, e posterior direcionamento para o ensino técnico, qual seria o papel da escola na formação dos valores dos estudantes? De que maneira essa formação fluída e sutil se concretiza? Existe ligação disso com as relações de poder que se estabelecem na sociedade? As respostas para tais questionamentos abarcam um leque imenso de possibilidades interpretativas, sendo necessário um recorte metodológico para podermos apreender alguns aspectos dessa realidade complexa e multifacetada.

O estudo das disputas que definiram a nomenclatura das escolas estabelece um recorte e uma proposta de análise acerca da formação desses valores e das relações de poder envolvidos, lançando mão do conceito de dominação simbólica (BOURDIEU, 1996; SOUZA, 2015). Em outras palavras, quando o aluno se depara com o espaço da escola, ele vai aprender o nome 
desse local, que será parte de sua vida por algum tempo, e por isso ganhará significado. Como foi o processo de decisão para o estabelecimento da nomenclatura dessas escolas, quais os significados dessa memória construída para a comunidade, em que medida isso reforça o poder da classe dominante tradicional, e como essa dominação ocorre de forma quase imperceptível e naturalizada são questões que certamente contribuem para a compreensão, não somente de aspectos da realidade educacional, mas também da formação de mecanismos opacos de dominação, que perpetuam determinados grupos e redes familiares no poder local.

\section{A Escola e a Construção de uma Memória Coletiva a Serviço de um Interesse de Classe}

A escola é espaço de disputa de poder, seja de forma direta ou não. As disputas por cargos, que determinam postos de comando e definem os orçamentos e demais questões econômicas nas instituições são exemplos dessa disputa mais evidente pelo poder dentro do ambiente escolar. Entretanto, existem também mecanismos menos explícitos nesse processo, como por exemplo, a definição das diretrizes pedagógicas a ser seguidas pelo corpo docente, o que tem o poder de orientar o processo educativo para caminhos mais ou menos críticos e questionadores acerca do sistema em que vivemos. Nesse sentido, a escolha de um projeto educacional crítico ao sistema pode contribuir para um trabalho educativo, onde a escola se contraponha a certos mecanismos de dominação classista, discutindo com o corpo discente as estruturas de desigualdade que existem na sociedade como um todo.

Mas não basta a escolha de um projeto pedagógico de conteúdo crítico para que a escola seja real espaço de questionamento e transformação das desigualdades sociais. Isso acontece porque a própria estrutura educacional escolar está assentada em pressupostos que tornam algumas diferenças sociais invisíveis dentro do próprio ambiente escolar, projetando uma pretensa igualdade meritocrática entre os estudantes, o que só serve para reforçar a desigualdade e o fracasso daqueles que, desde o início, desprovidos dos necessários capitais sociais e culturais ${ }^{2}$, já ingressaram em condições menos favoráveis dentro de todo o complexo processo de aprender.

\footnotetext{
${ }^{2}$ Os capitais são recursos mobilizadores (MATOS, 2009). Podem ser classificados como: “[...] econômico, que compreende a riqueza material, o dinheiro, as ações etc. (bens, patrimônios, trabalho)"; "[...] cultural, que compreende o conhecimento, as habilidades, as informações, etc."; “[...] social, correspondente ao conjunto de acessos sociais, que compreende o relacionamento e a rede de contatos" e "[...] simbólico, correspondente ao conjunto de rituais de reconhecimento social, e que compreende o prestígio, a honra etc. O capital simbólico é uma síntese dos demais (cultural, econômico e social)" (THIRY-CHERQUES, 2006, p. 38-39).
} 
Com efeito, para que sejam favorecidos os mais favorecidos e desfavorecidos os mais desfavorecidos, é necessário e suficiente que a escola ignore no âmbito dos conteúdos de ensino que transmite, dos métodos e técnicas de transmissão e dos critérios de avaliação as desigualdades culturais entre as crianças das diferentes classes sociais. Em outras palavras, tratando todos os educandos, por mais desiguais que sejam eles de fato, como iguais em direitos e deveres, o sistema escolar é levado a dar sua sansão às desigualdades iniciais diante da cultura. (BOURDIEU, 1998, p.53.)

Nesse sentido, por mais que existam brechas para a crítica e para o questionamento das estruturas de classe impostas na sociedade, a escola se constitui em boa medida como espaço de reprodução dos mecanismos e das estruturas de dominação presentes nas demais esferas sociais. O trabalho em sala de aula e o processo educacional como um todo ${ }^{3}$ cumprem o papel de reprodutores dos interesses hegemônicos das classes dominantes tradicionais, ainda que contraditoriamente seja também um caminho (talvez o único) para algumas parcelas das classes populares ascenderem socialmente.

$\mathrm{Na}$ pesquisa que estamos desenvolvendo acerca do processo de disputas de poder para a definição da nomenclatura das escolas estaduais de Curitiba (por meio principalmente de estudos genealógicos e prosopográficos ${ }^{4}$ ), o aspecto de reprodução da dominação classista no espaço escolar é fio condutor, uma vez que a hipótese de viés elitista para essas escolhas é um dado a ser confirmado ou refutado.

A construção de uma determinada memória histórica, que favorece a imagem das classes dominantes tradicionais no espaço da cidade, é um processo importante no âmbito da dominação simbólica, pois naturaliza a desigualdade, e reforça a ideia da meritocracia, do merecimento dos privilégios daqueles que os detém.

\begin{abstract}
A memória constitui também um espaço de divergências e confrontos, esquecimentos e silêncios, de práticas individuais e sociais e dos espaços de apropriação. Reconfiguração e recuperação das distintas visões do passado fazem parte da memória e de suas estratégias de lembrar, recordar, criar representações e construir elos identitários dos grupos sociais. E estratégias de dominação são mecanismos reveladores de manipulação da memória coletiva como instrumento de poder. (LEMOS $[\mathrm{s} / \mathrm{d}])$.
\end{abstract}

\footnotetext{
${ }^{3}$ Dentro da escola, não é somente no momento em que o professor ministra a aula que os valores carregados de dominação e violência simbólicas podem estar presentes. As escolhas dos livros didáticos, o estabelecimento dos projetos políticos pedagógicos das instituições, a atuação (ou a inexistência) das associações de pais, as diretrizes impostas pelas instâncias superiores governamentais e a definição da nomenclatura das instituições são exemplos de momentos e mecanismos onde os processos de dominação se fazem presentes de forma complementar, opaca e naturalizada.

${ }^{4}$ A "prosopografia é a investigação das características comuns de um grupo de atores na história por meio de um estudo coletivo de suas vidas". Tal método procura definir um universo a ser estudado (nascimento, morte, origens familiares) e estabelecer padrões possíveis a partir da justaposição das informações. Dessa maneira, os vários tipos de informações "são testados com o objetivo de encontrar tanto correlações internas quanto correlações com outras formas de comportamento ou ação" (STONE, 2011, p.115-116)
} 
Em outras palavras, significa referendar no passado as virtudes de determinado grupo ou família, como merecedores das benesses que hoje desfrutam, pois sempre foram trabalhadores, honestos e destaques de liderança na comunidade em que viviam ou se estabeleceram. Dessa maneira, a homenagem na nomeação de um nome de escola nada mais seria do que o justo reconhecimento de uma estirpe superior, e uma advertência às classes subalternas populares de sua posição de inferioridade, que deve ser aceita sem questionamentos. (GRANATO, 2017).

\section{Apontamentos Preliminares da pesquisa}

Curitiba possui 156 escolas de ensino regular. Para que seja possível o trabalho de pesquisa dentro das limitações de um projeto de mestrado, o recorte escolhido privilegiou as escolas com maior número de alunos (mil ou mais matrículas efetivadas no ano de 2018). Tal recorte não remete apenas a um dado quantitativo, apesar da importância dele, mas também chama a atenção para o fato de que, quanto mais periférica é a região, maior o tamanho da escola e o número de alunos que ela comporta. Por exemplo, no setor Santa Felicidade, onde estão escolas pertencentes a bairros mais centrais da cidade, existem 20 colégios estaduais, com um total de 10.902 matrículas efetivadas em 2018. Destas escolas, apenas uma, o Colégio Estadual Professor Francisco Zardo, possui mais de mil matrículas efetivadas no corrente ano (1610 matrículas para ser exata). Por outro lado, no setor Bairro Novo, onde estão localizadas escolas pertencentes a bairros periféricos, existem 18 colégios, com um total de 24.804 matrículas efetivadas em 2018. Destas escolas, 12 possuem mais de mil matrículas efetivadas no corrente ano. Se contarmos somente as escolas com mais de mil matrículas em 2018 no setor Bairro Novo, totalizamos o número de 20.124 matrículas efetivadas. Isso significa que, somente as escolas de maior porte do setor Bairro Novo, totalizam quase o dobro do número de alunos de todo setor Santa Felicidade. Portanto, o recorte do estudo genealógico e prosopográfico focando nas escolas com maior número de matrículas, também pode revelar dados acerca das regiões periféricas, que contemplam parcelas significativas das classes populares. ${ }^{5}$

\footnotetext{
5 Dados oficiais da Secretaria de Educação do Estado do Paraná, disponíveis em: <http://www.nre.seed.pr.gov.br/modules/conteudo/conteudo.php?conteudo=557>. Acesso: 13/04/2018 e http://www4.pr.gov.br/escolas/listaescolas.jsp. Acesso: 13/04/2018.
} 
No presente artigo, tomaremos como exemplos iniciais duas escolas estaduais de Curitiba: O Colégio Estadual Professor Francisco Zardo, situado em Santa Felicidade, e o Colégio Estadual Desembargador Guilherme Albuquerque Maranhão, no Tatuquara. Ou seja, uma escola da região central da cidade, e outra pertencente a um bairro da periferia.

\begin{tabular}{|c|c|}
\hline Francisco Zardo ${ }^{6}$ & \\
\hline Ano de Nascimento & - 1868 \\
\hline Local de Nascimento & $\begin{array}{l}\text { - Veneza - Itália } \\
\text { - Imigra para o Brasil em } 1888\end{array}$ \\
\hline Formação & - Escola Normal - professor primário \\
\hline Atuação Profissional & $\begin{array}{l}\text { - Inicia a atuação como professor primário em } 12 \text { de } \\
\text { novembro de } 1889 \text { em Santa Felicidade - Curitiba. } \\
\text { Ainda sem o curso do magistério e reconhecimento } \\
\text { oficial. } \\
\text { - Atuava em salas de aula montadas em casas cedidas } \\
\text { pelos moradores da colônia italiana de Santa } \\
\text { Felicidade. } \\
\text { - } 1892 \text { - conclui a escola normal e presta exames para } \\
\text { reconhecimento da habilitação do magistério. } \\
\text { - Girolamo Giareta, colono italiano dirigiu a primeira } \\
\text { escola étnico- comunitária da região de Santa } \\
\text { Felicidade até } 1890 \text {. } \\
\text { - Após a criação de uma escola mista (para meninos e } \\
\text { meninas), o governo provincial transferiu a direção } \\
\text { para uma professora brasileira - Maria Leocádia } \\
\text { Alves Araújo. }\end{array}$ \\
\hline
\end{tabular}

\footnotetext{
${ }^{6}$ As informações da presente tabela se encontram em SEED, [s/d].
} 


\begin{tabular}{|c|c|}
\hline & $\begin{array}{l}\text { - Contudo, a ideia de uma diretora mulher e não italiana } \\
\text { assumir o comando de uma escola para filhos de } \\
\text { colonos italianos irritava os membros da comunidade, } \\
\text { principalmente uma de suas lideranças, o Padre Pietro } \\
\text { Colbacchini - nomeado em } 1889 \text { Inspetor Paroquial } \\
\text { das Escolas nas colônias italianas. } \\
\text { - Diante da insistência do missionário, desqualificando o } \\
\text { trabalho da professora brasileira, o governo da } \\
\text { Província ainda nomeou duas outras professoras para a } \\
\text { direção da escola feminina étnico-comunitária de Santa } \\
\text { Felicidade: Maria Joana da Costa Lobato e Maria } \\
\text { de Jesus Duarte. } \\
\text { - Durante quatro meses de 1892, o professor Francisco } \\
\text { Zardo manteve a escola masculina com recursos dos } \\
\text { próprios colonos, enquanto o Padre Colbacchini } \\
\text { mantinha os esforços para que ele passasse a ser } \\
\text { remunerado com recursos do governo, e para que a } \\
\text { escola feminina deixasse de ser dirigida por } \\
\text { professoras brasileiras. A intenção do missionário era } \\
\text { que o próprio Zardo assumisse também a escola } \\
\text { feminina. } \\
\text { - Segundo os documentos da Província (MASCHIO, } \\
\text { 2012), o Padre Colbacchini não conseguiu levar o } \\
\text { Professor Francisco Zardo para a direção da escola } \\
\text { feminina de Santa Felicidade. Entretanto, no ano de } \\
\text { 1918, a filha do imigrante, Margarida Ângela Zardo } \\
\text { Miranda assumiu a função. }\end{array}$ \\
\hline $\begin{array}{l}\text { Relações e vínculos na } \\
\text { comunidade }\end{array}$ & $\begin{array}{l}\text { - João Batista e Margarida Culpi - amigos que } \\
\text { cederam o terreno onde seria construída a primeira } \\
\text { escola pública da região. }\end{array}$ \\
\hline Família & - Filha: Margarida Ângela Zardo Miranda . \\
\hline Falecimento & - 1931 \\
\hline ex & $\begin{array}{l}\text { - Em 1942, os moradores, tendo à frente os Srs. } \\
\text { Saturnino Miranda e Gumercindo de Oliveira } \\
\text { Godoy, deram início à construção da escola, com apoio } \\
\text { do então interventor Manoel Ribas e Prefeito Dr. } \\
\text { Rosaldo de Melo Leitão. } \\
\text { - Em } 1948 \text { o estabelecimento passou a se chamar "Grupo } \\
\text { Escolar Professor Francisco Zardo". } \\
\text { - Em } 17 \text { de dezembro de 1965, criou o Ginásio Estadual } \\
\text { de Santa Felicidade que em } 1966 \text { passou a denominar- } \\
\text { se, Ginásio Estadual João Mazzarotto. A escola } \\
\text { passou, então, a conviver com dois nomes, um para o } \\
\text { primário e outro para o ginásio. }\end{array}$ \\
\hline
\end{tabular}




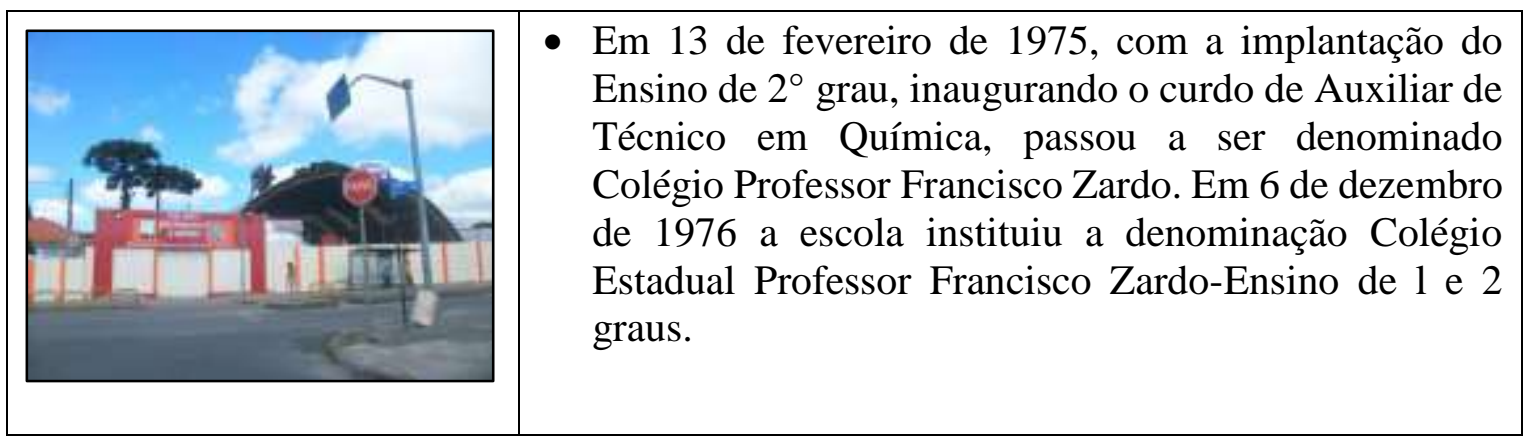

\begin{tabular}{|c|c|}
\hline $\begin{array}{l}\text { Desembargador Guilherme } \\
\text { Albuquerque Maranhão }{ }^{7}\end{array}$ & \\
\hline Ano de Nascimento & - $31 / 12 / 1915$ \\
\hline Local de Nascimento & - $\quad$ Manaus (AM) \\
\hline Formação & $\begin{array}{l}\text { - Realizou seus primeiros estudos no Colégio } \\
\text { Paranaense (1933). } \\
\text { - Bacharel em Direito pela Universidade do Paraná, } \\
\text { turma 1938. }\end{array}$ \\
\hline Atuação Profissional & $\begin{array}{l}\text { - No ano de 1940, foi nomeado para o cargo de } \\
\text { adjunto de promotor público de Reserva. Em } \\
\text { seguida, atuou nas comarcas de Foz do Iguaçu, } \\
\text { Paranaguá e Curitiba. Representou o Ministério } \\
\text { Público no Conselho Superior da Magistratura e } \\
\text { exerceu o cargo de Procurador Geral da Justiça. } \\
\text { - No dia } 17 \text { de agosto de 1984, foi alçado ao cargo de } \\
\text { desembargador do Tribunal de Justiça do Paraná, na } \\
\text { vaga do Quinto Constitucional destinada ao } \\
\text { Ministério Público. Aposentou-se em 1985. } \\
\text { - Foi condecorado com a medalha Infante D. Henrique } \\
\text { de Portugal. }\end{array}$ \\
\hline $\begin{array}{l}\text { Relações e vínculos na } \\
\text { comunidade }\end{array}$ & $\begin{array}{l}\text { - Fortes vínculos de amizade com a família Rego } \\
\text { Almeida. }\end{array}$ \\
\hline Família & $\begin{array}{l}\text { - Família de fidalgos portugueses, que chegam para } \\
\text { colonizar o Brasil ainda no século XVI. }\end{array}$ \\
\hline
\end{tabular}

\footnotetext{
${ }^{7}$ As informações da presente tabela se encontram em MARQUES, [s/d] e SEED, [s/d] a.
} 


\begin{tabular}{|c|c|}
\hline & $\begin{array}{l}\text { Estabeleceram sua autoridade em Pernambuco, Rio } \\
\text { - } \text { Algunde do Norte, Paraíba e Maranhão. } \\
\text { Paraná no final do século XIX e início do século XX } \\
\text { (José Pinheiro de Albuquerque Maranhão, João } \\
\text { Malta de } \\
\text { Albuquerque Maranhão e Luiz de Albuquerque } \\
\text { Maranhão). Os motivos da migração são as melhores } \\
\text { condições econômicas da região centro-sul e as } \\
\text { possibilidades de ingresso no serviço público do } \\
\text { recém estado emancipado do Paraná- } \\
\text { especialmente o poder judiciário. } \\
\text { Filho de João Malta de Albuquerque Maranhão e } \\
\text { Amélia de Oliveira Maranhão. } \\
\text { Seu irmão, Jerônimo de Albuquerque Maranhão, foi } \\
\text { também Procurador-Geral de Justiça (1985-1989). } \\
\text { Casou-se com Jandira Sales de Albuquerque } \\
\text { Maranhão, com quem teve seis filhos: Vera de } \\
\text { Albuquerque Maranhão, Carlos de Albuquerque } \\
\text { Maranhão, Mauro de Albuquerque Maranhão, } \\
\text { Edison de Albuquerque Maranhão, Jandira de } \\
\text { Albuquerque Maranhão e Christiane de Albuquerque } \\
\text { Maranhão. } \\
\text { Uma de suas filhas, Jandira de Albuquerque } \\
\text { Maranhão, é casada com Anibal Khury Filho, filho } \\
\text { do casal Anibal Khury (1924 -1999) e Niva Sabóia } \\
\text { Khury. São filhos do casal: Aníbal Khury Neto, } \\
\text { falecido; Alexandre Maranhão Khury; Daniel } \\
\text { Maranhão Khury e Rodrigo Maranhão Khury. } \\
\text { Alexandre Maranhão Khury é deputado pelo quarto } \\
\text { mandato na Assembleia Legislativa do Paraná. } \\
\text { Casado Paula Mussi Curi, filha do Empresário Luiz } \\
\text { Mussi e neta de Paulo Pimentel empresário do ramo } \\
\text { de comunicações e governador do Paraná de 1966 a } \\
\text { 1971. . }\end{array}$ \\
\hline Falecimento & • $\quad 17 / 06 / 1997$ \\
\hline A Escola & 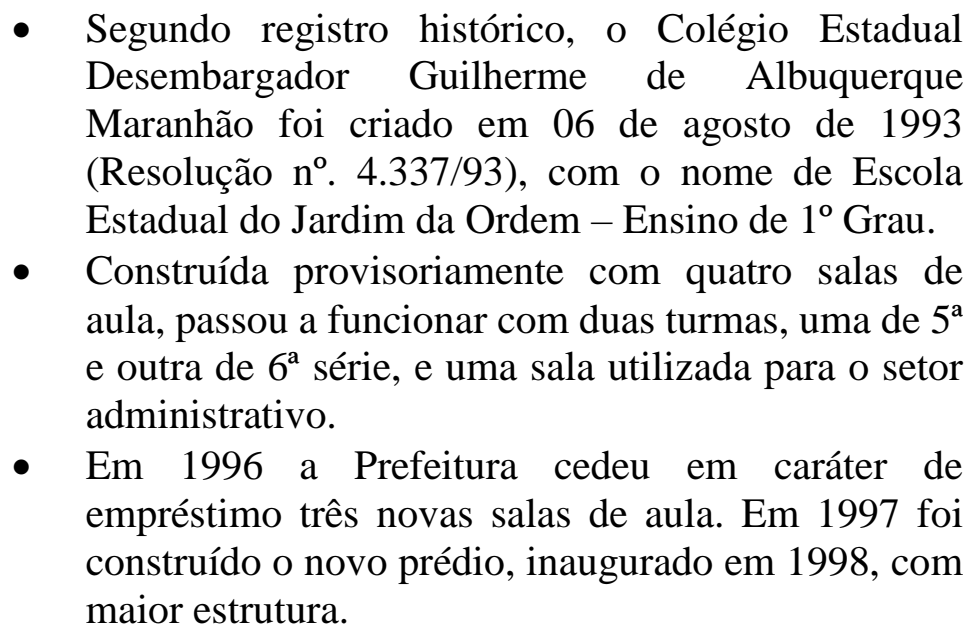 \\
\hline
\end{tabular}




\begin{tabular}{|l|l|}
\hline & Neste mesmo ano, teve seu nome alterado para \\
Colégio Estadual Desembargador Guilherme de \\
Albuquerque Maranhão - Ensino Fundamental e \\
Médio, em homenagem ao Desembargador \\
Guilherme de Albuquerque Maranhão, nascido em \\
Manaus, em 31 de Dezembro de 1915, mas que, pelo \\
amor devotado à Curitiba passou a ser considerado \\
um Curitibano legítimo.
\end{tabular}

\section{Considerações Finais}

Os dados preliminares da pesquisa genealógica revelam algumas informações interessantes, não só referentes às disputas para a nomeação destes homenageados (uma vez que a pesquisa ainda carece de dados mais completos sobre esse assunto), mas também no que diz respeito à própria trajetória dos escolhidos para batizar as escolas. No primeiro exemplo, a história do Professor Francisco Zardo, imigrante italiano, é marcada pela disputa entre representantes da colônia italiana em Curitiba e as autoridades estaduais, onde os representantes dos colonos empreenderam grande esforço para manter membros imigrantes na posição de professores das escolas étnico-comunitárias. A intenção mais evidente era a preservação da cultura originária imigrante, principalmente por meio da manutenção do ensino da língua italiana nessas colônias.

O segundo exemplo, a história do Desembargador Guilherme Albuquerque Maranhão revela uma linhagem secular e poderosa, que inicia já no período colonial sua trajetória como formadora da classe dominante tradicional, principalmente na região Nordeste do Brasil. Com a posterior migração de alguns de seus componentes para o estado do Paraná, tal família se estabelece no setor público, especialmente no judiciário. Atuando em conjunto com as demais oligarquias governamentais paranaenses, a estirpe dos Albuquerque Maranhão reafirma seus vínculos de poder, por meio do instrumento tradicional do casamento. Aliando-se à famílias tradicionais e importantes, como os Khury e Pimentel, garante sua posição de destaque e poder na região.

Um novo levantamento preliminar, com a obtenção de dados (disponíveis em mídias digitais e acervos da internet) referentes à formação e ocupação dos homenageados, revela que, das 52 escolas com mais de mil matrículas efetivadas em 2018, 44 possuem nomes de indivíduos homenageados, e as demais são escolas com nomes referentes à sua localização, sua área de ensino ou homenagens a santos católicos. Além disso, é possível verificar que a 
formação e a ocupação profissional desses 44 homenageados era bastante diversa, sendo que poderiam desempenhar funções em mais de uma área. Entretanto, considerando suas ocupações mais marcantes, é possível levantar que são homenageados:

- 17 professores;

- 09 ocupantes de cargos políticos;

- 02 religiosos católicos;

- 02 donos de cartório;

- 01 entalhador em madeira;

- 01 artista plástico;

- 01 policial militar;

- 01 poeta;

- 01 jornalista;

- 01 primeira dama do estado do Paraná;

- 01 piloto de aviação;

- 01 desembargador;

- 01 sapateiro;

- 01 médico;

- 01 banqueiro;

- 01 - outra situação ${ }^{8}$;

- 02 não encontrados na pesquisa ${ }^{9}$.

A tabela a seguir detalha o levantamento feito acerca da formação e ocupação dos 44 homenageados nas escolas com mais de mil matrículas efetivadas em 2018 em Curitiba:

1- Setor Centro

\begin{tabular}{|l|l|l|}
\hline \multicolumn{1}{|c|}{ Escolas } & \multicolumn{1}{|c|}{$\begin{array}{c}\text { Bairro } \\
\text { Wanderley (EF/EM/EP) }\end{array}$} & $\begin{array}{l}\text { Ocupação do Homenageado } \\
\text { (Nome da Escola) }\end{array}$ \\
\hline & Batel & $\begin{array}{l}\text { Nome completo Júlia } \\
\text { Wanderley Petrich. } \\
\text { Professora, primeira mulher } \\
\text { nomeada pelo Poder } \\
\text { Executivo do Paraná para } \\
\text { exercer o magistério, foi } \\
\text { diretora do Colégio } \\
\text { Tiradentes por 25 anos e } \\
\text { colaborava na elaboração de }\end{array}$ \\
\hline
\end{tabular}

\footnotetext{
${ }^{8}$ A informação se refere ao homenageado que dá nome à escola Aníbal Khury Neto, que era neto do deputado Anibal Khury, influente político paranaense. O homenageado não chegou à idade adulta, pois faleceu em Curitiba ainda aos 3 anos de idade (PEREIRA, 2016 a).

${ }^{9}$ Visto que a pesquisa se concentrou exclusivamente nesse momento em fontes disponíveis na internet, as informações não encontradas sobre essas duas escolas serão levantadas junto aos arquivos dessas instituições.
} 


\begin{tabular}{|c|c|c|}
\hline & & $\begin{array}{l}\text { artigos para os jornais } \\
\text { Operário Livre e } O \text { artista . }\end{array}$ \\
\hline $\begin{array}{l}\text { Colégio Estadual do Paraná } \\
\text { (EF/EM/EP) }\end{array}$ & Alto da Gloria & |------------------- \\
\hline $\begin{array}{l}\text { Colégio Estadual Professor } \\
\text { Loureiro Fernandes (EF/EM/EP) }\end{array}$ & Ahu de Baixo & $\begin{array}{l}\text { Professor - José Loureiro } \\
\text { Fernandes formou-se em } \\
\text { Medicina pela Faculdade } \\
\text { Nacional de Medicina do Rio } \\
\text { de Janeiro Antropólogo } \\
\text { autodidata e professor } \\
\text { universitário, participou da } \\
\text { criação de escolas e } \\
\text { faculdades e foi um dos } \\
\text { fundadores do Círculo de } \\
\text { Estudos Bandeirantes do } \\
\text { Paraná (CEB) e membro da } \\
\text { Academia Paranaense de } \\
\text { Letras. 11 }\end{array}$ \\
\hline $\begin{array}{l}\text { Instituto de Educação Prof. } \\
\text { Erasmo Pilotto (EF/EM/N) }\end{array}$ & Centro & $\begin{array}{l}\text { Ingressou no magistério em } \\
\text { Paranaguá, lecionou em } \\
\text { Curitiba e foi professor da } \\
\text { Escola Normal. Em } 1946 \\
\text { redigiu e coordenou o Plano } \\
\text { de governo do candidato ao } \\
\text { governo do Paraná, Moisés } \\
\text { Lupion. Em } 1949 \text { foi } \\
\text { Secretário de Educação e } \\
\text { Cultura durante o governo } \\
\text { Lupion e chegou ao cargo de } \\
\text { auditor do Tribunal de } \\
\text { Contas do estado. } \\
\text { Em } 1982 \text { recebeu da } \\
\text { Universidade Federal do } \\
\text { Paraná o título de Professor } \\
\text { Honoris Causa. } 12\end{array}$ \\
\hline
\end{tabular}

\section{2- Setor Boa Vista}

\begin{tabular}{|l|l|l|}
\hline \multicolumn{1}{|c|}{ Escolas } & \multicolumn{1}{|c|}{ Bairro } & \multicolumn{1}{|c|}{$\begin{array}{c}\text { Ocupação do Homenageado } \\
\text { (Nome da Escola) }\end{array}$} \\
\hline $\begin{array}{l}\text { Colégio Estadual Ângelo Gusso } \\
\text { (EF/EM) }\end{array}$ & Boa Vista & Entalhador em madeira. \\
\hline $\begin{array}{l}\text { Colégio Estadual Dona Branca } \\
\text { do Nascimento Miranda (EF/EM) }\end{array}$ & Tinguí & Professora. $^{\text {14 }}$ \\
\hline $\begin{array}{l}\text { Colégio Estadual Leôncio Correa } \\
\text { (EF/EM) }\end{array}$ & Bacacheri & $\begin{array}{l}\text { Advogado, escritor, } \\
\text { jornalista e político. }{ }^{15}\end{array}$ \\
\hline $\begin{array}{l}\text { Colégio Estadual Pilar Maturana } \\
\text { (EF/EM) }\end{array}$ & Bairro Alto & $\begin{array}{l}\text { Religiosa e educadora da }_{\text {Congregação Sagrado }} \\
\text { Coração de Jesus. }{ }^{16}\end{array}$ \\
\hline
\end{tabular}

${ }^{10} \mathrm{SEED},[\mathrm{s} / \mathrm{d}] \mathrm{b}$.

${ }^{11}$ UFPR, 2017.

12 OCEANO DE LETRAS, 2010.

13 SEED, [s/d] c.

${ }^{14}$ Idem, [s/d] d.

15 SOUZA, 2011.

16 SEED, [s/d] e. 


\begin{tabular}{|l|l|l|}
\hline $\begin{array}{l}\text { Colégio Estadual Professor } \\
\text { Algacyr M. Maeder (EF/EM) }\end{array}$ & Bairro Alto & $\begin{array}{l}\text { Professor, Reitor, escritor e } \\
\text { político. }\end{array}$ \\
\hline $\begin{array}{l}\text { Colégio Estadual Santa Cândida } \\
\text { (EF/EM) }\end{array}$ & Santa Cândida & $-\cdot-\cdot-\cdot-\cdot-\cdot-\cdot-\cdot---$ \\
\hline
\end{tabular}

3- Setor Santa Felicidade

\begin{tabular}{|l|l|l|}
\hline \multicolumn{1}{|c|}{ Escolas } & \multicolumn{1}{|c|}{ Bairro } & $\begin{array}{c}\text { Ocupação do Homenageado } \\
\text { (Nome da escola) }\end{array}$ \\
\hline $\begin{array}{l}\text { Colégio Estadual Professor } \\
\text { Francisco Zardo (EF/EM/EP) }\end{array}$ & Santa Felicidade & Professor. \\
\hline
\end{tabular}

4- Setor Portão

\begin{tabular}{|c|c|c|}
\hline Escolas & Bairro & $\begin{array}{c}\text { Ocupação do Homenageado } \\
\text { (Nome da escola) }\end{array}$ \\
\hline $\begin{array}{l}\text { Colégio Estadual Professor } \\
\text { Lysimaco Ferreira da Costa } \\
(\mathrm{EF} / \mathrm{EM})\end{array}$ & Água Verde & $\begin{array}{l}\text { Iniciou carreira militar na } \\
\text { juventude. Diretor do } \\
\text { Ginásio Paranaense entre } \\
1920 \text { e } 1928 \text {. Em } 1928 \\
\text { assumiu o cargo de } \\
\text { Secretário da Fazenda, } \\
\text { Indústria e Comércio do PR. } \\
\text { 19 }\end{array}$ \\
\hline $\begin{array}{l}\text { Colégio Estadual Pedro Macedo } \\
\text { (EF/EM/EP) }\end{array}$ & Portão & $\begin{array}{l}\text { Bacharel em Direito pela } \\
\text { Faculdade de Direito da } \\
\text { Universidade do Paraná, } \\
\text { fundador do Círculo de } \\
\text { Estudos Bandeirantes } \\
\text { (CEB), professor e artista } \\
\text { plástico. }{ }^{20}\end{array}$ \\
\hline $\begin{array}{l}\text { Colégio Estadual da Polícia } \\
\text { Militar Coronel PM Felippe de } \\
\text { Sousa Miranda (EF/EM) }\end{array}$ & Portão & $\begin{array}{c}\text { Policial Militar, professor, } \\
\text { advogado, médico, } \\
\text { farmacêutico e agrônomo. }\end{array}$ \\
\hline
\end{tabular}

5- Setor Cajuru

\begin{tabular}{|l|l|l|}
\hline \multicolumn{1}{|c|}{ Escolas } & \multicolumn{1}{|c|}{ Bairro } & $\begin{array}{l}\text { Ocupação do Homenageado } \\
\text { (Nome da escola) }\end{array}$ \\
\hline $\begin{array}{l}\text { Colégio Estadual Alfredo Parodi } \\
\text { (EF/EM) }\end{array}$ & Uberaba & $\begin{array}{l}\text { Professor e Diretor do } \\
\text { Colégio Iguassú em } \\
\text { Curitiba. 22 }\end{array}$ \\
\hline $\begin{array}{l}\text { Colégio Estadual Anibal Khury } \\
\text { Neto (EF/EM) }\end{array}$ & Uberaba & $\begin{array}{l}\text { Neto do Deputado e } \\
\text { Presidente Da Assembleia } \\
\text { Legislativa do Paraná } \\
\text { (ALEP) Aníbal Khury, } \\
\text { morreu aos três anos de } \\
\text { idade num acidente de } \\
\text { trânsito em frente ao Clube } \\
\text { Curitibano, na capital do } \\
\text { paranaense. 23 }\end{array}$ \\
\hline
\end{tabular}




\begin{tabular}{|c|c|c|}
\hline $\begin{array}{l}\text { Colégio Estadual Deputado } \\
\text { Olívio Belich (EF/EM) }\end{array}$ & Cajuru & $\begin{array}{l}\text { Juiz de paz, vereador, } \\
\text { prefeito e deputado estadual. } \\
24\end{array}$ \\
\hline $\begin{array}{l}\text { Colégio Estadual Paulo Leminski } \\
\text { (EF/EM/EProfs) }\end{array}$ & Tarumã & $\begin{array}{l}\text { Poeta, escritor, professor e } \\
\text { tradutor. }{ }^{25}\end{array}$ \\
\hline $\begin{array}{l}\text { Colégio Estadual Júlio Mesquita } \\
\text { (EF/EM/EProfs) }\end{array}$ & Jd. Das Américas & $\begin{array}{l}\text { Advogado, político e } \\
\text { jornalista (proprietário do } \\
\text { jornal } O \text { Estado de São } \\
\text { Paulo). }{ }^{26}\end{array}$ \\
\hline $\begin{array}{l}\text { Colégio Estadual Professor Nilo } \\
\text { Brandão (EF/EM) }\end{array}$ & Cajuru & $\begin{array}{l}\text { Professor, escritor, diretor e } \\
\text { fundador do Colégio Rui } \\
\text { Barbosa (Ctba) e diretor da } \\
\text { revista Correio dos } \\
\text { Ferroviários. }{ }^{27} \\
\end{array}$ \\
\hline $\begin{array}{l}\text { Escola Estadual Santa Rosa } \\
\text { (EF/EM) }\end{array}$ & Cajuru & 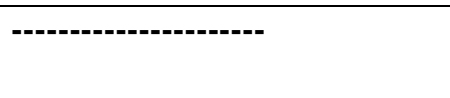 \\
\hline $\begin{array}{l}\text { Colégio Estadual Senhorinha } \\
\text { Moraes Sarmento (EF/EM) }\end{array}$ & Cajuru & Professora e pedagoga. ${ }^{28}$ \\
\hline
\end{tabular}

6- Setor Pinheirinho

\begin{tabular}{|c|c|c|}
\hline Escolas & Bairro & $\begin{array}{c}\text { Ocupação do Homenageado } \\
\text { (Nome da escola) }\end{array}$ \\
\hline $\begin{array}{l}\text { Colégio Estadual Emilio de } \\
\text { Menezes (EF/EM) }\end{array}$ & Capão Raso & Jornalista e poeta. $^{29}$ \\
\hline $\begin{array}{l}\text { Colégio Estadual Jayme Canet } \\
\text { (EF/EM) }\end{array}$ & Xaxim & $\begin{array}{l}\text { Empresário agropecuarista } \\
\text { e político paranaense, eleito } \\
\text { indiretamente governador } \\
\text { do estado em 1974. }\end{array}$ \\
\hline $\begin{array}{l}\text { Colégio Estadual La Salle } \\
\text { (EF/EM) }\end{array}$ & Pinheirinho & 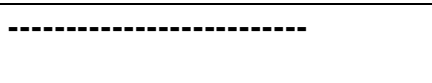 \\
\hline $\begin{array}{l}\text { Colégio Estadual Professor } \\
\text { Narciso Mendes (EF/EM) }\end{array}$ & Xaxim & $\begin{array}{l}\text { Professor, contabilista, foi } \\
\text { vereador pelo município de } \\
\text { São José dos Pinhais e foi } \\
\text { Secretário e Educação e } \\
\text { Cultura no governo de } \\
\text { Moisés Lupion. } 31\end{array}$ \\
\hline $\begin{array}{l}\text { Colégio Estadual São Pedro } \\
\text { Apóstolo (EF/EM/EP) }\end{array}$ & Xaxim & 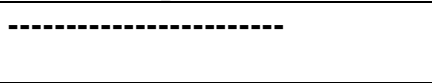 \\
\hline $\begin{array}{l}\text { Colégio Estadual Yvone } \\
\text { Pimentel (EF/EM) }\end{array}$ & Novo Mundo & $\begin{array}{l}\text { Filha de grandes } \\
\text { proprietários de terras e }\end{array}$ \\
\hline
\end{tabular}

${ }^{17}$ MARTINS, 2013.

18 SEED, [s/d] f).

${ }^{19}$ FERREIRA, [s/d].

${ }^{20}$ AGÊNCIA DE NOTÍCIAS ESTADO DO PARANÁ, 2006 e CÍRCULO DE ESTUDOS BANDEIRANTES, [s/d].

${ }^{21} \mathrm{SESP},[\mathrm{s} / \mathrm{d}]$.

${ }^{22}$ MILARCH, 1985.

${ }^{23}$ PEREIRA, 2016 a.

${ }^{24}$ GRATANO, 2016.

${ }^{25}$ FRAZÃO, 2017.

${ }^{26}$ JORNAL O ESTADO DE SÃO PAULO, [s/d].

${ }^{27}$ CURITIBA SPACE. [s/d].

${ }^{28} \mathrm{SEED},[\mathrm{s} / \mathrm{d}] \mathrm{g}$.

${ }^{29}$ ABL, [s/d] e ENCICLOPÉDIA ITAÚ CULTURAL DE ARTE E CULTURA BRASILEIRAS, 2018.

${ }^{30}$ GOVERNO DO ESTADO DO PARANÁ, [s/d].

${ }^{31} \mathrm{SEED},[\mathrm{s} / \mathrm{d}] \mathrm{h}$. 


\begin{tabular}{|l|l|l|}
\hline & $\begin{array}{l}\text { usinas no norte do Paraná, } \\
\text { casada com o ex-governador } \\
\text { do Paraná Paulo Pimentel. }{ }^{32}\end{array}$ \\
\hline
\end{tabular}

7- Setor Boqueirão

\begin{tabular}{|c|c|c|}
\hline Escolas & Bairro & $\begin{array}{l}\text { Ocupação do Homenageado } \\
\text { (Nome da escola) }\end{array}$ \\
\hline $\begin{array}{l}\text { Centro Estadual de Educação } \\
\text { Profissional de Curitiba - Ensino } \\
\text { Profissionalizante. }\end{array}$ & Boqueirão & 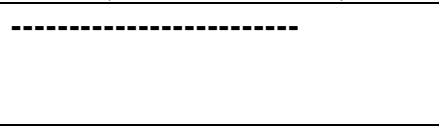 \\
\hline $\begin{array}{l}\text { Colégio Estadual Euzébio da } \\
\text { Mota (EF/EM) }\end{array}$ & Boqueirão & $\begin{array}{l}\text { Bacharel em Direito, foi } \\
\text { deputado estadual (1874- } \\
\text { 1875) e professor de } \\
\text { Filosofia e Retórica. }{ }^{33} \\
\end{array}$ \\
\hline $\begin{array}{l}\text { Colégio Estadual Polivalente de } \\
\text { Curitiba (EF/EM) }\end{array}$ & Boqueirão & 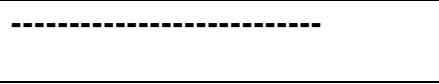 \\
\hline $\begin{array}{l}\text { Colégio Estadual Professor Jose } \\
\text { Guimarães (EM/EP) }\end{array}$ & Vila Hauer & Professor ${ }^{34}$ \\
\hline $\begin{array}{l}\text { Colégio Estadual Roberto Langer } \\
\mathrm{Jr}(\mathrm{EF} / \mathrm{EM})\end{array}$ & Boqueirão & Piloto de aviação. ${ }^{35}$ \\
\hline $\begin{array}{l}\text { Colégio Estadual São Paulo } \\
\text { Apóstolo (EF/EM) }\end{array}$ & Uberaba & |---------------------------- \\
\hline
\end{tabular}

\section{8- Setor Bairro Novo}

\begin{tabular}{|l|l|l|}
\hline \multicolumn{1}{|c|}{ Escolas } & \multicolumn{1}{|c|}{ Bairro } & $\begin{array}{l}\text { Ocupação do Homenageado } \\
\text { (Nome da escola) }\end{array}$ \\
\hline $\begin{array}{l}\text { Colégio Estadual Benedicto João } \\
\text { Cordeiro (EF/EM/EProfs) }\end{array}$ & Sítio Cercado & $\begin{array}{l}\text { Professor do ensino } \\
\text { primário, bacharel em } \\
\text { Pedagogia e delegado pela } \\
\text { Secretaria de Educação do } \\
\text { Paraná. 36 }\end{array}$ \\
\hline $\begin{array}{l}\text { Colégio Estadual Desembargador } \\
\text { Guilherme Albuquerque } \\
\text { Maranhão (EF/EM) }\end{array}$ & Tatuquara & $\begin{array}{l}\text { Promotor, Procurador Geral } \\
\text { do Estado do Paraná e } \\
\text { Desembargador. 37 }\end{array}$ \\
\hline $\begin{array}{l}\text { Colégio Estadual Flávio Ferreira } \\
\text { da Luz (EF/EM) }\end{array}$ & Sítio Cercado & $\begin{array}{l}\text { Bacharel em Direito, titular } \\
\text { do Cartório de Registro de } \\
\text { Imóveis do 1 Distrito da } \\
\text { Capital e Presidente da } \\
\text { Federação Espírita do } \\
\text { Paraná. 38 }\end{array}$ \\
\hline $\begin{array}{l}\text { Colégio Estadual Professor } \\
\text { Guido Arzua (EF/EM) }\end{array}$ & Sítio Cercado & $\begin{array}{l}\text { Professor de Língua e } \\
\text { Literatura Luso Brasileiras, } \\
\text { professor Auxiliar da } \\
\text { Cadeira de Direito Civil, da } \\
\text { Faculdade de Direito da } \\
\text { Universidade Federal do }\end{array}$ \\
\hline
\end{tabular}

32 BRAGA, 2009.

${ }^{33}$ SEED, [s/d] i.

${ }^{34}$ Idem, [s/d] j.

${ }^{35}$ O ALBATROZ, 2005.

${ }^{36}$ SEED, [s/d] k.

${ }^{37}$ MARQUES, [s/d].

${ }^{38}$ SEED, [s/d] 1. 


\begin{tabular}{|c|c|c|}
\hline & & $\begin{array}{l}\text { Paraná (1966/1971) e } \\
\text { Diretor do Departamento de } \\
\text { Educação, da Secretaria de } \\
\text { Educação do Estado do } \\
\text { Paraná. } 39\end{array}$ \\
\hline $\begin{array}{l}\text { Colégio Estadual Hasdrubal } \\
\text { Bellegard (EF/EM/EP). }\end{array}$ & Sítio Cercado & $\begin{array}{l}\text { Formado em Agronomia, } \\
\text { Ciências Contábeis e } \\
\text { Ciências Econômicas. } \\
\text { Diretor do Departamento } \\
\text { Econômico da Federação } \\
\text { das Indústrias do Paraná e } \\
\text { como Presidente da } \\
\text { Distribuidora Cummis } \\
\text { Diesel do Paraná. Em 1947, } \\
\text { foi suplente de Deputado } \\
\text { Estadual pelo Partido Social } \\
\text { Progressista. } 40\end{array}$ \\
\hline $\begin{array}{l}\text { Escola Estadual Professora Iara } \\
\text { Bergmann (EF/EM) }\end{array}$ & Ganchinho & Professora. ${ }^{41}$ \\
\hline $\begin{array}{l}\text { Escola Estadual Inez Vicente } \\
\text { Borocz (EF/EM) }\end{array}$ & Sítio Cercado & $\begin{array}{l}\text { Pesquisa em andamento. } \\
\text { Nenhuma informação } \\
\text { encontrada na internet. }\end{array}$ \\
\hline $\begin{array}{l}\text { Colégio Estadual Moradias } \\
\text { Monteiro Lobato (EF/EM) }\end{array}$ & Tatuquara & 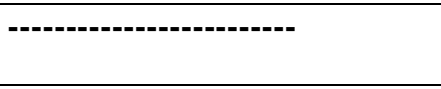 \\
\hline $\begin{array}{l}\text { Colégio Estadual Nirlei Medeiros } \\
\text { (EF/EM) }\end{array}$ & Campo de Santana & $\begin{array}{l}\text { Pesquisa em andamento. } \\
\text { Nenhuma informação } \\
\text { encontrada na internet. }\end{array}$ \\
\hline $\begin{array}{l}\text { Colégio Estadual Padre Cláudio } \\
\text { Morelli (EF/EM) }\end{array}$ & Umbará & $\begin{array}{l}\text { Pároco da Igreja Católica no } \\
\text { bairro Umbará entre } 1912 \text { e } \\
1915.42\end{array}$ \\
\hline $\begin{array}{l}\text { Colégio Estadual Professor } \\
\text { Teobaldo Leonardo Kletemberg } \\
\text { (EF/EM) }\end{array}$ & Sítio Cercado & $\begin{array}{l}\text { Professor de História, } \\
\text { Diretor da Escola Estadual } \\
\text { Dom Orione; Coordenador } \\
\text { da Comissão Executiva } \\
\text { Regional de Curitiba dos } \\
\text { Exames Supletivos 1a } \\
\text { Região; Coordenador na } \\
\text { Área de Estudos Sociais no } \\
\text { Colégio Estadual do Paraná; } \\
\text { Diretor da Escola Estadual } \\
\text { Santa Isabel; diretor do } \\
\text { Colégio Estadual Pe. } \\
\text { Silvestre Kandora; } \\
\text { Assistente de Núcleo } \\
\text { Regional de Educação de } \\
\text { Curitiba. } 43\end{array}$ \\
\hline $\begin{array}{l}\text { Colégio Estadual Professora } \\
\text { Maria Gai Grendel (EF/EM) }\end{array}$ & Caximba & Professora. ${ }^{44}$ \\
\hline
\end{tabular}

\section{9- Setor CIC}

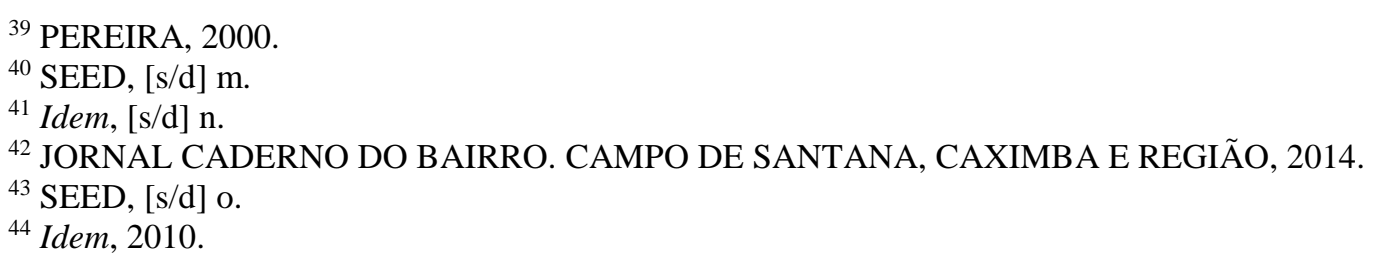




\begin{tabular}{|c|c|c|}
\hline Escolas & Bairro & $\begin{array}{c}\begin{array}{c}\text { Ocupação do Homenageado } \\
\text { (Nome da escola) }\end{array} \\
\end{array}$ \\
\hline $\begin{array}{l}\text { Colégio Estadual Avelino } \\
\text { Antônio Vieira (EF/EM) }\end{array}$ & Fazendinha & $\begin{array}{l}\text { Banqueiro, diretor de } \\
\text { diversas instituições } \\
\text { financeiras, entre elas o } \\
\text { Banco Mercantil e Industrial } \\
\text { do Paraná S/A } \\
\text { (BAMERINDUS). }{ }^{45}\end{array}$ \\
\hline $\begin{array}{l}\text { Colégio Estadual Professor } \\
\text { Brasílio Vicente de Castro } \\
\text { (EF/EM) }\end{array}$ & CIC & $\begin{array}{l}\text { Médico, presidente do } \\
\text { Conselho Regional de } \\
\text { Medicina do Paraná (CRM - } \\
\text { PR) entre } 1966 \text { e } 1968 .{ }^{46}\end{array}$ \\
\hline $\begin{array}{l}\text { Colégio Estadual Eurides } \\
\text { Brandão (EF/EM) }\end{array}$ & $\mathrm{CIC}$ & $\begin{array}{l}\text { Cartorário no município de } \\
\text { Irati - PR, era pai de } \\
\text { Hermas Brandão, deputado } \\
\text { estadual e presidente da } \\
\text { Assembleia Legislativa do } \\
\text { Paraná (ALEP) por diversas } \\
\text { vezes. }^{47}\end{array}$ \\
\hline $\begin{array}{l}\text { Colégio Estadual Marli Queiroz } \\
\text { Azevedo (EF/EM) }\end{array}$ & $\mathrm{CIC}$ & $\begin{array}{l}\text { Professora da rede pública } \\
\text { de Curitiba, colaborou como } \\
\text { Diretora Social da } \\
\text { Associação de Pais e Mestres } \\
\text { do Colégio Marista Santa } \\
\text { Maria. No Instituo de } \\
\text { Engenharia do Paraná e na } \\
\text { Associação Brasileira dos } \\
\text { Engenheiros Civis } \\
\text { coordenou programas de } \\
\text { atividades para as esposas } \\
\text { de engenheiros. Participou } \\
\text { também de campanhas e } \\
\text { atividades assistenciais do } \\
\text { Rotary Club de Curitiba. }{ }^{48}\end{array}$ \\
\hline $\begin{array}{l}\text { Colégio Estadual Professora } \\
\text { Hildegard Sondahl (EF/EM) }\end{array}$ & CIC & $\begin{array}{l}\text { Professora e diretora do } \\
\text { Colégio Padre João Bagozzi. } \\
49\end{array}$ \\
\hline $\begin{array}{l}\text { Colégio Estadual Rodolpho } \\
\text { Zaninelli (EF/EM/EP) }\end{array}$ & CIC & $\begin{array}{l}\text { Sapateiro. Foi o primeiro } \\
\text { profissional a produzir } \\
\text { sapatos para pessoas com } \\
\text { deficiência física em } \\
\text { Curitiba. }{ }^{50} \\
\end{array}$ \\
\hline $\begin{array}{l}\text { Colégio Estadual Teotônio Vilela } \\
\text { (EF/EM) }\end{array}$ & CIC & $\begin{array}{l}\text { Agropecuarista, deputado } \\
\text { estadual, vice-governador de } \\
\text { Alagoas e Senador. }{ }^{51}\end{array}$ \\
\hline
\end{tabular}

${ }^{45}$ Ibidem, [s/d] p.

${ }^{46}$ CFM, 2004.

${ }^{47}$ SEED, [s/d] q.

${ }^{48} \mathrm{Idem},[\mathrm{s} / \mathrm{d}] \mathrm{r}$.

${ }^{49}$ PACHECO, 2015.

${ }^{50}$ CMC, 2018.

${ }^{51}$ RAMALHO, [s/d]. 
Diante desses dados, o prosseguimento e aprofundamento da pesquisa é que poderá revelar se a hipótese de caráter elitista classista para a nomeação dos homenageados nas escolas públicas estaduais de Curitiba se sustenta. Contudo, existem alguns indícios que essa premissa pode proceder, uma vez que o grande número de nomes ligados aos grupos tradicionais poderosos e/ou as etnias de origem europeia branca é evidente.

\section{Referências}

ACADEMIA BRASILEIRA DE LETRAS - ABL. "Emilio de Meneses/ Biografia". [s/d]. Disponível em: 〈http://www.academia.org.br/academicos/emilio-de-meneses/biografia>. Acesso em: 29/05/2018.

AGÊNCIA DE NOTÍCIAS ESTADO DO PARANÁ. "Colégio Estadual Pedro Macedo comemora 50 anos". 2006.2 Disponível $\langle$ http://www.historico.aen.pr.gov.br/modules/noticias/article.php?storyid=23038>. Acesso em: 30/05/2018.

BOMENY, H. "E ele voltou... o segundo governo Vargas - A educação no segundo governo Vargas". 2017.

Disponível

em:

$<$ http://cpdoc.fgv.br/producao/dossies/AEraVargas2/artigos/EleVoltou/Educacao>. Acesso em: 25/04/2018.

BOURDIEU, P. “A escola conservadora”. In: NOGUEIRA, M. A.; CATANI, A. (orgs). Pierre Bourdieu - escritos de educação. Petrópolis: Vozes, 1988, p.53.

Razões práticas: sobre a teoria da ação. Campinas: Papirus, 1996.

BRAGA, S.S. "Pimentel, Paulo". 2009. Disponível em: <http://www.fgv.br/cpdoc/acervo/dicionarios/verbete-biografico/paulo-cruz-pimentel>.

Acesso em: 29/05/2018.

BRASIL. "Legislação Informatizada - LEI DE 15 DE OUTUBRO DE 1827 - Publicação Original”. 2009. Disponível em: <http://www2.camara.leg.br/legin/fed/lei_sn/1824-1899/lei38398-15-outubro-1827-566692-publicacaooriginal-90222-pl.html>. Acesso em: 24/04/2018.

CÂMARA MUNICIPAL DE CURITIBA - CMC. "Nossa memória - História de Curitiba e da Câmara Municipal - 1693 - 2014". 2018. Disponível em: <https://www.cmc.pr.gov.br/rua_hist.php>. Acesso em: 30/05/2018.

CÍRCULO DE ESTUDOS BANDEIRANTES. "Histórico". [s/d]. Disponível em: <http://www3.pucpr.br/circuloestudos/historico.php〉. Acesso em: 30/05/2018.

CONSELHO FEDERAL DE MEDICINA - CFM.. "Lista de Presidentes do Conselho Regional de Medicina do Paraná”. 2004. Disponível em 
$<$ http://portal.cfm.org.br/index.php?option=com_content\&view=article\&id=975:\&catid=3>. Acesso em: 29/05/2018.

CURITIBA SPACE. "Quem foi: Nilo Brandão". [s/d]. Disponível em <http://curitibaspace.com.br/quem-foi-nilo-brandao/>. Acesso em: 29/05/2018.

DICK, M. V. P. A. A dinâmica dos nomes na cidade de São Paulo 1554-1897. São Paulo: Annablume, 1997.

ENCICLOPÉDIA ITAÚ CULTURAL DE ARTE E CULTURA BRASILEIRAS."Emílio de Menezes". 2018. Disponível em: <http://enciclopedia.itaucultural.org.br/pessoa3146/emiliode-menezes>. Acesso em: 29/05/2018.

FERREIRA, S.C. "Lysímaco Ferreira da Costa. Um educador. Memória e esquecimento". [s/d]. Disponível em: 〈http://www2.faced.ufu.br/colubhe06/anais/arquivos/236SusanaFerreira.pdf $>$. Acesso em: 28/05/2018.

FRAZÃO, D. "Biografia de Paulo Leminski." 2017. Disponível em: http://www.casacivil.pr.gov.br/modules/conteudo/conteudo.php?conteudo=81>. Acesso: 29/05/2018.

GRANATO, N.C. "Relações de poder e dominação nos nomes das escolas públicas em Curitiba, Brasil.". $2017 \quad$ Disponível em $\langle$ http://alas2017.easyplanners.info/opc/tl/2277_natalia_cristina_granato.pdf $>$. Acesso em: 29/04/2018.

GRATANO, N.C. O campo político paranaense no contexto do golpe de 1964 e suas lutas políticas. 2016 Dissertação de mestrado. Universidade Federal do Paraná, p. 251.

HEY, A.P.; CATANI, A.M. "Bourdieu e a educação". 2018. Disponível em: $<$ https://revistacult.uol.com.br/home/bourdieu-e-a-educacao/>. Acesso em:27/04/2018.

JORNAL CADERNO DO BAIRRO. CAMPO DE SANTANA, CAXIMBA E REGIÃO. "A comunidade de Umbará celebra a história da educação". 2014. Disponível em: <http://www.cadernodobairro.com.br/santana/umbara/429-a-comunidade-de-umbara-celebraa-historia-da-educacao.html>. Acesso: 29/05/2018.

JORNAL O ESTADO DE SÃO PAULO. "Julio Mesquita". [s/d]. Disponível em $<$ http://acervo.estadao.com.br/noticias/personalidades,julio-mesquita, $753,0 . h t m>$. Acesso em: 28/05/2018.

KAMINSKI H.L. Elites e parentesco no sistema judicial paranaense. .2013. 199p. Dissertação de Mestrado em Sociologia. Setor de Ciências Humanas, Letras e Artes. Universidade Federal do Paraná.

LEMOS, M.T.T.B. “As Estratégias da Memória e a Construção da Identidade”. [s/d]. Disponível em: <www.epublicacoes.uerj.br/index.php/latinidade/article/download/17996/13309>.__Acesso em: 27/04/2018. 
MAGALHÃES, L,D,R. "A educação na Primeira República”. [s/d]. Disponível em <http://www.histedbr.fe.unicamp.br/navegando/artigos_frames/artigo_057.html >. Acesso em: 24/04/2018.

MARQUES, R.J.. "Des. Guilherme Albuquerque Maranhão". [s/d]. Disponível em: $<$ https://www.tjpr.jus.br/desembargadores-tjpr-museu/-/asset_publisher/V8xr/content/desguilherme-albuquerque-maranhao/397262? inheritRedirect=false>. Acesso em: 29/04/2018.

MARTINS, J.C. "No Dia da Escola, as polêmicas matemáticas do professor Maeder". 2013. Disponível em: <http://www.cmc.pr.gov.br/ass_det.php?not=20049\#\&panel1-1>. Acesso em: 28/05/2018.

MARX, K.; ENGELS, F. A ideologia alemã. São Paulo: Martins Fontes, 2002.

MASCHIO, E.C.F. A escolarização dos imigrantes e de seus descendentes nas colônias italianas de Curitiba, entre táticas e estratégias (1875-1930). 2012. 341p. Tese de Doutorado em Educação. Setor de Educação. Universidade Federal do Paraná.

__ "As escolas étnico-comunitárias no processo de escolarização dos imigrantes italianos em Curitiba". $2013 . \quad$ Disponível em: $\langle$ http://educere.bruc.com.br/arquivo/pdf2013/7240_4233.pdf $\rangle$. Acesso em:28/04/2018.

MATOS, H. Capital social e comunicação: interfaces e articulações. São Paulo: Summus, 2009.

MILARCH, A. "Morte da memória do nosso ensino". 1985. Disponível em: $<$ http://www.millarch.org/artigo/morte-da-memoria-de-nosso-ensino $>$ Acesso em: 29/05/2018.

MINISTÉRIO PÚBLICO DO PARANÁ - MP-PR. "Guilherme de Albuquerque Maranhão". [s/d]. Disponível em: <http://www.memorial.mppr.mp.br/pagina-55.html>. Acesso em:29/04/2018.

MONTEIRO, J. M. A política como negócio de família: para uma sociologia política das elites e do poder político. São Paulo: Liber Ars, 2016.

NASCIMENTO, M. I. M. "O império e as primeiras tentativas de organização da educação nacional (1822-1889)". [s/d]. Disponível em: <http://www.histedbr.fe.unicamp.br/navegando/periodo_imperial_intro.html\#_ftn1>. Acesso em: 30/05/2018.

O ALBATROZ. Aeroclube do Paraná”. 2005. Disponível em: $<$ http://albatrozpqd.com.br/sbbi/index.php?option=com_content\&view=article\&id=76:aeroclu be-do-parana-o-comeco\&catid=46:1972\&Itemid=67>. Acesso em: 30/05/2018.

OCEANO DE LETRAS. "Erasmo Pilotto (1910 - 1992)". 2010. Disponível em: <https://nuhtaradahab.wordpress.com/2010/08/25/erasmo-pilotto-1910-1992/>. Acesso em: 28/05/2018. 
OLIVEIRA, R. C. Na teia do nepotismo: sociologia política das relações de parentesco e poder político no Paraná e no Brasil. Curitiba: Insigth, 2012.

PACHECO, S. C. “Assembleia homenageia os 60 anos do Grupo Educacional Bagozzi”. 2015. Disponível em: 〈http://www.alep.pr.gov.br/divulgacao/noticias/assembleia-homenageia-os60-anos-do-grupo-educacional-bagozzi>. Acesso em: 29/05/2018.

PEREIRA, A.I. "Homenagem a Guido Arzua: O 'MR. Rotary". 2000. Disponível em: $<$ http://www.curitibaoeste.org.br/web.asp? RotaSource=1\&gestao=0\&categ=padrao\&id=15>. Acesso em: 29/05/2018.

PEREIRA, F.M. "Breve estudo genealógico de Cecílio do Rego Almeida". In: Revista NEP, Curitiba, 2016, v.2, n.2, pp. 26-41.

"Casamento como estratégia de ampliação de poder: um breve estudo genealógico da família Khury”. In: OLIVEIRA, R.C. (org.). Nepotismo, parentesco e mulheres. Curitiba: RM Editores, 2016.

RAMALHO, R. "Quem foi Teotônio Brandão Vilela?”. [s/d]. Disponível em: < http://www.arcos.org.br/artigos/quem-foi-teotonio-brandao-vilela/>. Acesso em: 28/05/2018.

RAMOS, L.M.P.C. (2001) "Educação das Classes Populares: o que mudou nas últimas décadas". Teias, jan/jun, ano 2, n³, [s/d]. pp 1-14.

RIBEIRO, P. R. M. "História da educação escolar no Brasil: notas para uma reflexão". Paidéia, fev/jul, 1993, no 4, pp. 15-30.

SCHMIDT, M. A; DIVARDIM, T; SOBANSKI, A. Ocupa 2016: memórias de jovens estudantes. Curitiba: W\&A Editores, 2016.

SECRETARIA DA SEGURANÇA PÚBLICA E ADMINISTRAÇÃO PENITENCIÁRIA DO PARANÁ SESP. "Felipe de Sousa Miranda." [s/d]. Disponível em: $<$ http://www.pmpr.pr.gov.br/modules/conteudo/conteudo.php?conteudo=108>. Acesso em: $28 / 05 / 2018$.

SECRETARIA DE EDUCAÇÃO DO ESTADO DO PARANÁ - SEED. "Histórico do Colégio Francisco Zardo - EFMP”. [s/d]. Disponível em: $<$ http://www.ctafranciscozardo.seed.pr.gov.br/modules/conteudo/conteudo.php?conteudo=12 >. Acesso em: 28/04/2018.

" “Colégio Estadual Des. Guilherme A. Maranhão - EFM.”. ([s/d] a). Disponível em: $<$ http://www.ctaguilhermemaranhao.seed.pr.gov.br/modules/conteudo/conteudo.php?conteud o=10>. Acesso:29/04/2018.

"Biografia Professora Júlia Wanderley". ([s/d] b). Disponível em: <http://www.ctajuliawanderley.seed.pr.gov.br/modules/conteudo/conteudo.php? conteudo=11 >. Acesso em: 29/05/2018. 
"Histórico".

([s/d]

c).

Disponível

em:

$\langle$ http://www.ctaangelogusso.seed.pr.gov.br/modules/conteudo/conteudo.php? conteudo=1 $>$.

Acesso em: 28/05/2018.

"História

da Instituição". ([s/d]

d). Disponível em:

$<$ http://www.ctabrancamiranda.seed.pr.gov.br/modules/conteudo/conteudo.php?conteudo=14

>. Acesso em: 28/05/2018.

"História".

([s/d]

e).

Disponível

em:

$\langle$ http://www.ctapilarmaturana.seed.pr.gov.br/modules/conteudo/conteudo.php?conteudo=1 > Acesso em: 28/05/2018.

. "Histórico do Colégio Francisco Zardo - EFMP". ([s/d] f). Disponível em: $<$ http://www.ctafranciscozardo.seed.pr.gov.br/modules/conteudo/conteudo.php?conteudo=12

>. Acesso em: 27/05/2018.

. “Quem foi Senhorinha de Moraes Sarmento?”. ([s/d] g). Disponível em: $\langle$ http://www.ctasenhorinha.seed.pr.gov.br/modules/conteudo/conteudo.php?conteudo=19>. Acesso: 29/05/2018.

"Narciso de Azevedo Mendes". ([s/d] h). Disponível em $<$ http://www.ctanarcisomendes.seed.pr.gov.br/modules/conteudo/conteudo.php?conteudo=11 >. Acesso em: 29/05/2018.

. "Eusébio Silveira da Mota. Histórico do Patrono". ([s/d] i). Disponível em: <http://www.ctaeuzebiomota.seed.pr.gov.br/modules/conteudo/conteudo.php?conteudo=18 >. Acesso em: 29/05/2018.

"Histórico".

$([\mathrm{s} / \mathrm{d}]$

j).

Disponível

em:

$\langle$ http://www.ctajoseguimaraes.seed.pr.gov.br/modules/conteudo/conteudo.php? conteudo=9 $>$. Acesso em: 29/05/2018.

"Histórico".

$([\mathrm{s} / \mathrm{d}]$

$\mathrm{k})$.

Disponível

em:

<http://www.ctabenedictocordeiro.seed.pr.gov.br/modules/conteudo/conteudo.php?conteudo= 20>. Acesso em: 29/05/2018.

"Flávio Ferreira da Luz". ([s/d] 1). Disponível em: http://www.ctahasdrubalbellegard.seed.pr.gov.br/modules/conteudo/conteudo.php? conteudo= 12 Acesso em: 29/05/2018.

“Apresentação". $\quad([\mathrm{s} / \mathrm{d}] \quad \mathrm{n}) . \quad$ Disponível em:

<http://www.ctaiarabergmann.seed.pr.gov.br/modules/noticias/>. Acesso em: 30/05/2018.

. "Colégio Est. Prof. Teobaldo L. Kletemberg - EFM". ([s/d] o). Disponível em: $\langle$ http://www.ctateobaldo.seed.pr.gov.br/modules/conteudo/conteudo.php?conteudo $=60\rangle$. Acesso em: 29/05/2018.

"Histórico".

$([\mathrm{s} / \mathrm{d}]$

p).

Disponível

em:

<http://www.ctaavelinovieira.seed.pr.gov.br/modules/conteudo/conteudo.php? conteudo=1 $>$. Acesso em: 29/05/2018. 
"Histórico".

$([\mathrm{s} / \mathrm{d}]$

q).

Disponível

em:

$\langle$ http://www.ctaeuridesbrandao.seed.pr.gov.br/modules/conteudo/conteudo.php? conteudo=12 z. Acesso em: 29/05/2018.

"Histórico do estabelecimento". ([s/d] r). Disponível em $\langle$ http://www.ctamarliazevedo.seed.pr.gov.br/modules/conteudo/conteudo.php?conteudo=11 > Acesso em: 29/05/2018.

. "Região sul de Curitiba ganha novo colégio". 2010. Disponível em: $\langle$ http://www.educacao.pr.gov.br/modules/noticias/article.php?storyid=1673>. Acesso em: 29/05/2018.

SILVA, J.E. "Pesquisa historiográfica em educação: o apostolado positivista do Brasil e a instrução pública no Brasil”. [s/d]. Disponível em: $<$ http://www.histedbr.fe.unicamp.br/navegando/artigos_frames/artigo_047.html >. Acesso em: 25/04/2018.

SOUZA, J.. A tolice da inteligência brasileira: ou como o país se deixa manipular pela elite. São Paulo: LeYa, 2015.

SOUZA, S, N. "Leôncio Correia, Patrono de uma Escola Municipal na Ilha de Guaratiba". 2011. Disponível em: <http://www.rioeduca.net/blogViews.php?id=1192>. Acesso em: 28/05/2018.

STONE, L. "Prosopografia". In: Revista de Sociologia e Política, jun., 2011, vol. 19, nº 39, p. 115-137.

THIRY-CHERQUES, H. R. "Pierre Bourdieu: a teoria na prática". In: Rev. Adm. Pública, 2006, vol.40, n.1, pp.27-53.

UNIVERSIDADE FEDERAL DO PARANÁ - UFPR. "Colóquio sobre José Loureiro Fernandes acontece no Circulo de Estudos Bandeirantes - 31/05”. 2017. Disponível em: $<$ http://www.ufpr.br/portalufpr/eventos/coloquio-sobre-jose-loureiro-fernandes-acontece-nocirculo-de-estudos-bandeirantes/>. Acesso em: 30/05/2018. 